\title{
Alga Ecklonia bicyclis, Tribulus terrestris, and Glucosamine Oligosaccharide Improve Erectile Function, Sexual Quality of Life, and Ejaculation Function in Patients with Moderate Mild-Moderate Erectile Dysfunction: A Prospective, Randomized, Placebo-Controlled, Single-Blinded Study
}

\author{
Salvatore Sansalone, ${ }^{1}$ Rosario Leonardi, ${ }^{2}$ Gabriele Antonini, ${ }^{3}$ \\ Antonio Vitarelli, ${ }^{4}$ Giuseppe Vespasiani, ${ }^{1}$ Dragoslav Basic, ${ }^{5}$ Giuseppe Morgia, ${ }^{6}$ \\ Sebastiano Cimino, ${ }^{6}$ and Giorgio Ivan Russo ${ }^{6}$ \\ ${ }^{1}$ Department of Experimental Medicine and Surgery, Tor Vergata University of Rome, Rome, Italy \\ ${ }^{2}$ Centro Uro Andrologico, Acireale, Italy \\ ${ }^{3}$ Department of Urology "U. Bracci”, La Sapienza University of Rome, Rome, Italy \\ ${ }^{4}$ Urologia Universitaria II, Azienda Ospedaliera Policlinico Bari, Bari, Italy \\ ${ }^{5}$ Clinic of Urology, Clinical Center Nis, Nis, Serbia \\ ${ }^{6}$ School of Medicine Policlinico Hospital, Department of Urology, University of Catania, Catania, Italy \\ Correspondence should be addressed to Giorgio Ivan Russo; giorgioivan@virgilio.it
}

Received 18 March 2014; Accepted 1 June 2014; Published 20 July 2014

Academic Editor: Ralf Herwig

Copyright (C) 2014 Salvatore Sansalone et al. This is an open access article distributed under the Creative Commons Attribution License, which permits unrestricted use, distribution, and reproduction in any medium, provided the original work is properly cited.

\begin{abstract}
We aimed to evaluate the efficacy of oral therapy with alga Ecklonia bicyclis, Tribulus terrestris, and glucosamine oligosaccharide (Tradamix TX1000) in patients with erectile dysfunction (ED) at 3 months of follow-up. From January 2013 to September 2013, 177 patients diagnosed with mild-moderate ED (IIEF-EF $<26)$ were enrolled in this multicenter, single-blinded, placebo-controlled study and randomized in Group A (Tradamix, $n=87$ ) and Group B (placebo, $n=90)$ ). Penile color Doppler ultrasound measures, IIEF-15 questionnaire, male sexual health questionnaire-ejaculation disorder (MSHQ-EjD), and sexual quality of life (SQoL-M) were collected. We observed significant changes of the IIEF-15 in Group A (mean difference: 11.54; $P<0.05$ ) at 3 months versus Group B $(P<0.05)$. PSV $(P<0.05)$, IIEF-intercourse satisfaction $(P<0.05)$, IIEF-orgasmic function (mean $P<0.05)$, IIEF-sexual desire $(P<0.05)$, IIEF-overall satisfaction $(P<0.05)$, MSHQ-EjD (mean difference: $1.21 ; P<0.05$ ), and SQoL-M (mean difference: 10.2; $P<0.05)$ were significantly changed in Group A versus baseline and Group B. Patients with moderate arterial dysfunction showed significant increase of PSV $(P<0.05)$, IIEF-EF $(P<0.05)$, MSHQ-EjD $(P<0.05)$, and SQoL-M $(P<0.05)$ in Group A. Therapy with Tradamix improves erectile and ejaculation function and sexual quality of life in patients with mild-moderate ED and in particular for those with moderate arterial dysfunction.
\end{abstract}

\section{Introduction}

All over the world, erectile dysfunction (ED) is considered one of the most diffuse sexual disorders. The prevalence rate of ED increases with age and with concomitant morbidities. To this regard, erectile dysfunction (ED) has progressively emerged as an important indicator of men's overall health, due to the very closed relationship to concomitant comorbidities [1-4].

Several observational studies recently demonstrated that ED is associated with different comorbid condition and overall poorer male health $[5,6]$, but also ED may significantly 
increase the risk of cardiovascular disease (CVD), coronary heart disease, stroke [7], and all-cause mortality [8-11], and this increase is probably independent from conventional cardiovascular risk factors [9] and glycometabolic control [12].

Based on these considerations, phosphodiesterase-5 inhibitors (PDE5-i) have become the most popular treatment and are currently the first line monotherapy for ED [13].

However, it should be taken into account that some patients with complex ED may not be responders to PDE5-I monotherapy [14]. Furthermore, this category of drugs is not depicted from side effects that could impair pharmacological adherence.

The most common reported side effects are headache, muscular pains, hot flushes, tearing, and so on that can affect normal sexual intercourse [15]. It is also generally known that ED may be associated with serum total testosterone (TT) alterations. In fact, TT in men begins to decline in the late third or early fourth decade and diminish at a constant rate thereafter [16].

In this general context, studies on natural compounds have been conducted with the intention to limit side effects and to maintain efficacy $[17,18]$. A new natural compound made of alga Ecklonia bicyclis, Tribulus terrestris, and glucosamine oligosaccharide has been diffused in order to improve male sexual function in elderly men, particularly libido and possible erectile dysfunction. Ecklonia bicyclis has radical scavenger activity 10-100 times more powerful than any other polifenol terrestris plants, which have only 3-4 phenolic and rings that are commonly considered among the most effective antioxidant molecules. The protodioscin is a steroidal saponin, which is about $90 \%$ of the extract obtained from aerial parts of Tribulus terrestris. Thanks to its particular steroidal structure it has an androgen mimetic action, binding and activating the receptor of testosterone. So this substance is able to increase the endogenous production of testosterone, dihydrotestosterone, hormone luteinizing hormone (LH), dehydroepiandrosterone (DHEA), and dehydroepiandrosterone sulfate (DHEAS).

glucosamine oligosaccharide acts both on nonadrenergic and noncholinergic system (NANC) and on endothelial cell system as a strong nitric oxide synthetase (NOS) simulator [16].

The aim of this prospective multicenter randomized, single-blinded, placebo-controlled study was to evaluate the efficacy and tolerability of the combination therapy with alga Ecklonia bicyclis, Tribulus terrestris, and glucosamine oligosaccharide in patients mild-moderate erectile dysfunction at 3 months of follow-up.

\section{Patients and Methods}

From January 2013 to September 2013, 214 patients diagnosed with mild-moderate ED (IIEF-EF < 26) were entered in this prospective multicenter randomized, single-blinded, placebo-controlled study. All subjects gave written informed consent before entering the study, which was conducted in accordance with the Declaration of Helsinki, and the Human Ethics Committee approved the study protocol (Serbian
Ministry Of Education and Science, Grant No175092). All patients underwent preliminary assessment including a detailed medical and sexual history to evaluate the presence of risk factors such as diabetes mellitus, hypertension, dyslipidaemia, and smoking. All subjects were self-administered the IIEF-15 item questionnaire and the Male Sexual Health Ques-tionnaire-Ejaculation Disorder (MSHQ-EjD) and sexual quality of life instrument for men (SQoL-M).

The primary inclusion criteria were a minimum age of 18 years, a diagnosis of nonendocrinological ED according to the National Institutes of Health statement on ED, 1 naïve to treatment for ED, a stable heterosexual relationship for at least the previous 6 months, and a steady relationship with the same female partner.

Exclusion criteria were as follows: severe ED (IIEF-EF < 11), previous medical or surgical treatments for $\mathrm{ED}$, any medical treatment for sexual dysfunction before or during the study, congenital or acquired penile curvature or chordee with hypospadias, age $>75$ years, hypogonadism (total testosterone level of $<8 \mathrm{nmol}$ or serum testosterone in the range of 8-11 nM and free testosterone $<220 \mathrm{pmol}$, assessed at least on two occasions), and end diastolic velocity $(\mathrm{EDV})>5 \mathrm{~cm} / \mathrm{s}$ at penile color doppler ultrasound (CDU).

All patients were also subjected to a thorough physical examination. To be able to exclude organic sexual dysfunctions and other underlying illnesses, fasting blood glucose level, urinalysis, complete blood count, sex hormones, and prolactin levels were measured.

All measurements were conducted by a single physician unaware of the treatment status.

Patients were randomized according to a computer generated random sequence with a 1:1 ratio in two treatment groups, namely, Group A and Group B. The first group received one tablet orally twice a day for 3 months and one tablet consisted of $300 \mathrm{mg}$ of alga Ecklonia bicyclis, $450 \mathrm{mg}$ of Tribulus terrestris and $250 \mathrm{mg}$ of glucosamine oligosaccharide (Tradamix TX1000, Tradapharma Sagl, Switzerland), while the second received one table twice a day for 3 months of placebo. We monitored adverse events on the light of common terminology criteria for adverse events (CTCAE) guidelines.

2.1. Main Outcome Measures. The primary efficacy outcome was the change from baseline to end point ( 3 months) for the IIEF-15. Secondary outcomes were the change from baseline to end point of IIEF-15 subscore, MSHQ-EJD, SQoL-M, and PSV. Safety assessments included treatment-emergent adverse events (TEAEs), serious AEs (SAEs), and orthostatic vital signs (blood pressure and heart rate).

2.2. Study Population. The study sample of 170 was powered for an approximately 10-point difference of the IIEF-15 using a two-sided type I error $=0.05$ and type II error $=0.1(90 \%$ power), requiring patients per group. The maximum sample size was set to 100 subjects per group, allowing for a $15 \%$ dropout rate. 
TABLE 1: Baseline characteristics of patients enrolled.

\begin{tabular}{|c|c|c|}
\hline & $\begin{array}{c}\text { Group A } \\
\text { (TRADAMIX } \\
\text { TX 1000) }\end{array}$ & $\begin{array}{l}\text { Group B } \\
\text { (Placebo) }\end{array}$ \\
\hline Number of patients & 87 & 90 \\
\hline Age $(y r)$, mean $\pm S D$ & $63.92 \pm 9.3$ & $65.37 \pm 8.81$ \\
\hline $\mathrm{BMI}\left(\mathrm{Kg} / \mathrm{m}^{2}\right)$, mean $\pm \mathrm{SD}$ & $26.36 \pm 3.0$ & $25.2 \pm 3.5$ \\
\hline Hypertension, $n(\%)$ & $40(44.94)$ & $42(46.66)$ \\
\hline Dyslipidemia, $n(\%)$ & $24(27.58)$ & $2(25.5)$ \\
\hline Diabetes, $n(\%)$ & 17 (19.54) & $18(20.0)$ \\
\hline Total testosterone, mean & $14.69 \pm 1.25$ & $13.26 \pm 1.02$ \\
\hline Smoking habit, $n(\%)$ & $40(39.21)$ & $38(38.0)$ \\
\hline IIEF-EF, mean \pm SD & $21.16 \pm 4.08$ & $20.71 \pm 3.77$ \\
\hline IIEF-IS, mean \pm SD & $5.80 \pm 2.07$ & $6.06 \pm 1.91$ \\
\hline $\mathrm{IIEF}-\mathrm{OF}$, mean $\pm \mathrm{SD}$ & $5.11 \pm 1.23$ & $5.37 \pm 1.37$ \\
\hline IIEF-SD, mean \pm SD & $7.97 \pm 1.69$ & $7.80 \pm 1.81$ \\
\hline IIEF-OS, mean \pm SD & $4.89 \pm 1.66$ & $4.86 \pm 1.44$ \\
\hline MSHQ-EjD, mean \pm SD & $14.89 \pm 3.09$ & $14.50 \pm 2.87$ \\
\hline SQoL-M, mean \pm SD & $54.21 \pm 2.11$ & $55.87 \pm 2.35$ \\
\hline PSV, mean \pm SD & $31.52 \pm 6.60$ & $30.02 \pm 5.56$ \\
\hline $\mathrm{EDV}$, mean $\pm \mathrm{SD}$ & $1.5 \pm 1.0$ & $1.2 \pm 2.0$ \\
\hline $\begin{array}{l}\text { Normal arterial function } \\
(\mathrm{PSV} \geq 35 \mathrm{~cm} / \mathrm{s}), n(\%)\end{array}$ & $36(35.3)$ & $30(33.3)$ \\
\hline $\begin{array}{l}\text { Moderate arterial dysfunction } \\
(\mathrm{PSV} \geq 25 \text { and }<35 \mathrm{~cm} / \mathrm{s}), n(\%)\end{array}$ & $31(30.4)$ & $29(32.2)$ \\
\hline $\begin{array}{l}\text { Severe arterial dysfunction } \\
(\mathrm{PSV}<25 \mathrm{~cm} / \mathrm{s}), n(\%)\end{array}$ & $20(19.6)$ & $22(24.4)$ \\
\hline
\end{tabular}

BMI = Body Mass Index; IIEF-EF = International Index of Erectile FunctionErectile Function; IIEF-IS = International Index of Erectile FunctionIntercourse Satisfaction; IIEF-OF = International Index of Erectile FunctionOrgasmic Function; IIEF-SD = International Index of Erectile FunctionSexual Desire; IIEF-OS = International Index of Erectile Function-Overall Satisfaction; MSHS-EJD = Male Sexual Health Questionnaire-Ejaculation Disorder; SQoL-M = sexual quality of life instrument for men; PSV = peak systolic velocity; EDV = end diastolic velocity.

2.3. Statistical Analysis. At baseline, the independent sample 2 -tailed $t$-test was used to compare variables. For categorical parameters, chi-square test was applied. Changes from baseline to end of therapy were analysed using ranked one-way analysis of variance (ANOVA) with a term for treatment group. According to the penile Doppler ultrasound analysis, patients were divided into three categories: normal arterial function (NAF) (PSV $\geq 35 \mathrm{~cm} / \mathrm{s}$ ), moderate arterial dysfunction (MAD) (PSV $\geq 25$ and $<35 \mathrm{~cm} / \mathrm{s}$ ), and severe arterial dysfunction (SAD) (PSV $<25 \mathrm{~cm} / \mathrm{s})$. Treatment group differences for primary and secondary end points were determined using post hoc analysis. Data were reported as means \pm standard deviation (SD) or median and nominal $P$ values were presented. For all statistical comparisons, significance was considered as $P<0.05$.

\section{Results}

Table 1 lists the baseline characteristics of patients enrolled. Of the 214 patients, 14 (6.54\%) were excluded from the study because they did not meet the entry criteria. Of the 200 patients randomized, 87 and 90 subjects in Group A and in Group B completed the study protocol. The flow chart of this study is presented in Figure 1.

3.1. Main Outcome Measures. Table 2 lists the mean change differences from baseline to 3 months relative to main outcome measures. When concerning the primary endpoint of this study, we observed significant changes of the IIEF-15 in Group A (mean difference: 11.54; $P<0.05$ ) at 3 months versus Group B at the intergroup analysis (mean difference: 10.22; $P<0.05$ ). In Group A, significant differences from baseline to last follow-up were observed relative to PSV (mean difference: $1.36 \mathrm{~cm} / \mathrm{s} ; P<0.05$ ), IIEF-IS (mean difference: 1.72; $P<0.05$ ), IIEF-OF (mean difference: 2.2; $P<0.05$ ), IIEF-SD (mean difference: 1.03; $P<0.05$ ), IIEF-OS (mean difference: 2.51; $P<0.05$ ), MSHQ-EjD (mean difference: 1.21; $P<0.05$ ), and SQoL-M (mean difference: $10.2 ; P<0.05)$. In Group $\mathrm{A}$, patients with moderate arterial dysfunction showed significant increase of IIEF-EF (mean difference: 1.82; $P<0.05$ ), PSV (mean difference: 1.56; $P<0.05$ ), MSHQ-EjD (mean difference: 1.23; $P<0.05$ ), and SQoL-M (mean difference: 11.65; $P<$ 0.05 ) from baseline to 3 months. Significant differences were found at the intergroup analysis when considering previous outcome measures (Table 2) and (Figure 2). Patients with normal arterial function and with severe arterial dysfunction of Group A did not report improvement of penile CDU measures after treatment. When considering serum TT and EDV, both groups did not show any difference after 3 months. All subjects included in the study protocol tolerated treatments, and none reported adverse events.

\section{Discussion}

Several studies have established that reactive oxygen ROS, especially superoxide anion and hydrogen peroxide, are important signaling molecules in cardiovascular cells $[19,20]$. Enhanced superoxide production increases NO inactivation and leads to an accumulation of peroxynitrites and hydrogen peroxide [21]. ROS participate in growth, apoptosis, and the migration of vascular smooth muscle cells, in the modulation of endothelial function (including endothelium-dependent relaxation and expression of a proinflammatory phenotype), and in the modification of the extracellular matrix [2224]. All of these events play important roles in endothelial dysfunction, suggesting that the sources of ROS and the signaling pathways that they modify may represent important therapeutic targets [25].

All these findings have determined the diffusion of several herbal extract with the intention of targeting previous pathways.

An interesting in vivo and in vitro animal investigations of a mixture of herbal extracts from $T$. terrestris and $C$. officinalis were conducted to investigate their relaxation effects and the mechanisms of action on penile erection. T. terrestris extract, C. officinalis extract, and the mixture of both extracts showed concentration-dependent relaxation effects 


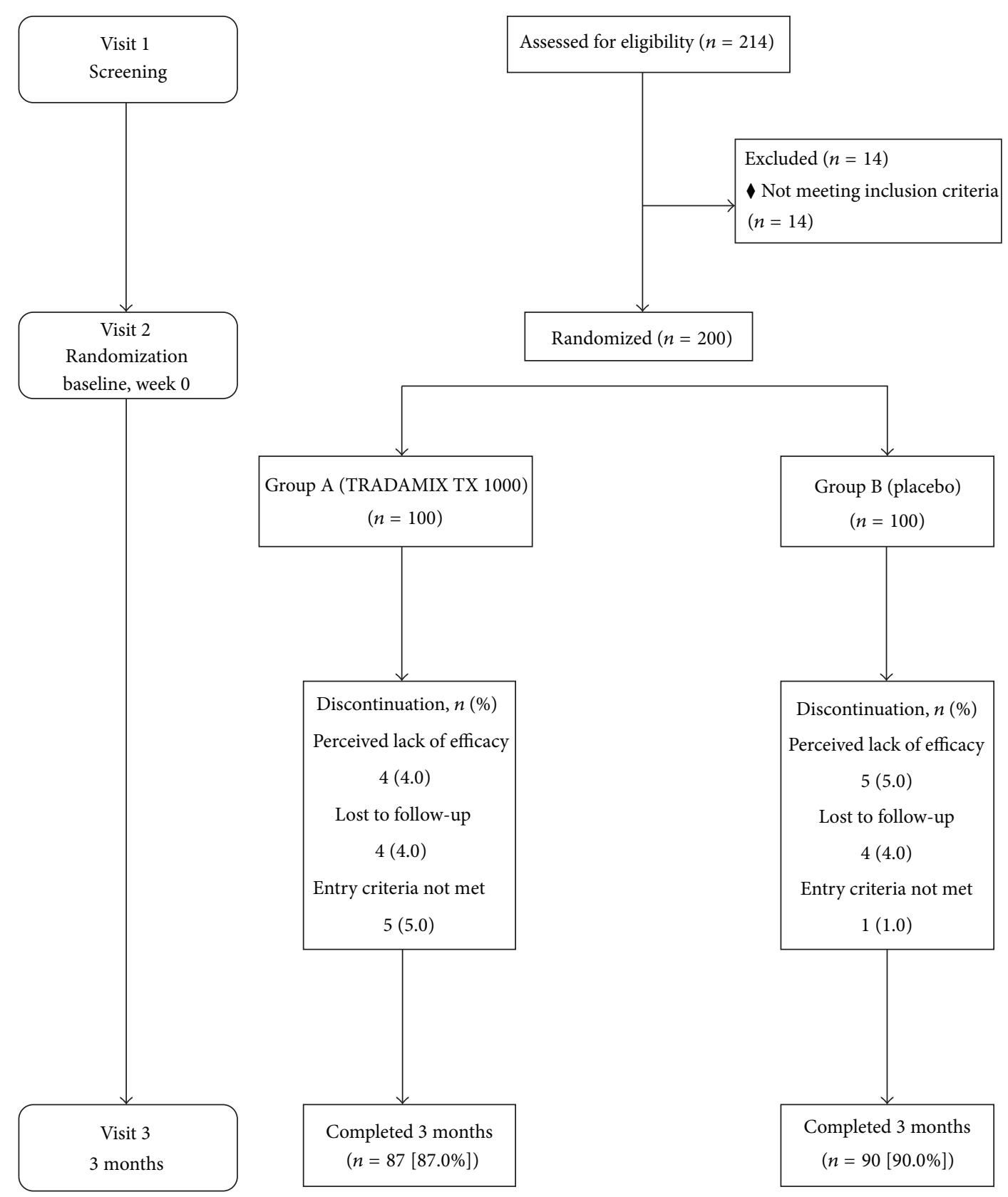

FIGURE 1: Disposition of subjects. Subject consolidated standards of reporting trials (CONSORT) diagram.

of the corpus cavernosum. Therefore, endothelium appears to be an important location of action of T. terrestris extract, functioning in relaxation mainly via NOS and exhibited relaxation effects mainly through cAMP and partly through cGMP [26].

It can be supposed that because herbal extracts do not contain a single ingredient but are a combination of multiple compounds, it would not be appropriate to expect a mechanism of action similar to that of a single compound such as a PDE-5 inhibitor. C. officinalis extract appears to exhibit relaxation effects by acting directly on the smooth muscle cells of the CC, not through the above pathway.
With the administration of the mixture of extracts, cAMP concentration in the CC increased significantly. Based on the previous results, the extracts studied appear to exhibit relaxation effects on the CC mainly through cAMP and partly through cGMP.

This can be explained by the multiple mechanism of action of these compounds on several targets with the consequent therapeutical efficacy.

Based on our results and considering all subdomains of 15-question International Index of Erectile Function, therapy with multiple antioxidants was significantly superior in improving intercourse satisfaction, sexual desire, orgasmic 
TABLE 2: Mean changes from baseline to 3 months for primary and secondary outcomes.

\begin{tabular}{|c|c|c|}
\hline & Group A & Group B \\
\hline IIEF-15, mean \pm SD & $11.54 \pm 2.47^{\mathrm{a}, \mathrm{b}}$ & $1.32 \pm 2.67$ \\
\hline IIEF-EF, mean \pm SD & $0.35 \pm 1.42$ & $0.04 \pm 1.00$ \\
\hline IIEF-IS, mean \pm SD & $1.72 \pm 1.63^{\mathrm{a}, \mathrm{b}}$ & $0.05 \pm 2.15$ \\
\hline $\mathrm{IIEF}-\mathrm{OF}$, mean $\pm \mathrm{SD}$ & $2.20 \pm 1.51^{\mathrm{a}, \mathrm{b}}$ & $0.08 \pm 1.77$ \\
\hline IIEF-SD, mean \pm SD & $1.03 \pm 1.35^{\mathrm{a}, \mathrm{b}}$ & $0.41 \pm 0.34$ \\
\hline IIEF-OS, mean \pm SD & $2.51 \pm 1.45^{\mathrm{a}, \mathrm{b}}$ & $0.57 \pm 0.39$ \\
\hline MSHQ-EjD, mean \pm SD & $1.21 \pm 2.03^{\mathrm{a}, \mathrm{b}}$ & $0.24 \pm 1.07$ \\
\hline SQoL-M, mean \pm SD & $10.20 \pm 3.77^{\mathrm{a}, \mathrm{b}}$ & $1.24 \pm 2.53$ \\
\hline $\mathrm{PSV}(\mathrm{cm} / \mathrm{s})$, mean $\pm \mathrm{SD}$ & $1.36 \pm 0.75^{\mathrm{a}, \mathrm{b}}$ & $0.21 \pm 0.44$ \\
\hline $\mathrm{EDV}(\mathrm{cm} / \mathrm{s})$, mean $\pm \mathrm{SD}$ & $0.24 \pm 1.0$ & $0.31 \pm 0.9$ \\
\hline $\begin{array}{l}\text { Total testosterone }(\mathrm{nmol} / \mathrm{L}) \text {, } \\
\text { mean } \pm \mathrm{SD}\end{array}$ & $14.26 \pm 2.05$ & $13.31 \pm 1.32$ \\
\hline \multicolumn{3}{|l|}{$\begin{array}{l}\text { Normal arterial function } \\
(P S V \geq 35 \mathrm{~cm} / \mathrm{s} \text { ) subgroup }\end{array}$} \\
\hline IIEF-EF, mean \pm SD & $0.94 \pm 3.68$ & $0.10 \pm 4.10$ \\
\hline $\operatorname{PSV}(\mathrm{cm} / \mathrm{s})$, mean \pm SD & $0.16 \pm 0.75$ & $0.10 \pm 0.87$ \\
\hline MSHQ-EJD, mean \pm SD & $1.41 \pm 1.85^{\mathrm{a}, \mathrm{b}}$ & $0.32 \pm 1.54$ \\
\hline SQoL-M, mean \pm SD & $8.76 \pm 3.65$ & $1.41 \pm 3.21$ \\
\hline \multicolumn{3}{|c|}{$\begin{array}{l}\text { Moderate arterial dysfunction } \\
(\mathrm{PSV} \geq 25 \text { and }<35 \mathrm{~cm} / \mathrm{s} \text { ) subgroup }\end{array}$} \\
\hline IIEF-EF, mean \pm SD & $1.82 \pm 3.08^{\mathrm{a}, \mathrm{b}}$ & $0.16 \pm 2.69$ \\
\hline $\operatorname{PSV}(\mathrm{cm} / \mathrm{s})$, mean $\pm \mathrm{SD}$ & $1.56 \pm 0.82^{\mathrm{a}, \mathrm{b}}$ & $0.23 \pm 0.63$ \\
\hline MSHQ-EJD, mean \pm SD & $1.23 \pm 1.84^{\mathrm{a}, \mathrm{b}}$ & $0.11 \pm 1.52$ \\
\hline SQoL-M, mean \pm SD & $11.65 \pm 3.12^{\mathrm{a}, \mathrm{b}}$ & $1.18 \pm 2.87$ \\
\hline \multicolumn{3}{|l|}{$\begin{array}{l}\text { Severe arterial dysfunction } \\
(\mathrm{PSV}<25 \mathrm{~cm} / \mathrm{s} \text { ) subgroup }\end{array}$} \\
\hline IIEF-EF, mean \pm SD & $0.54 \pm 2.77$ & $0.23 \pm 2.41$ \\
\hline $\mathrm{PSV}(\mathrm{cm} / \mathrm{s})$, mean $\pm \mathrm{SD}$ & $0.05 \pm 0.52$ & $0.09 \pm 0.74$ \\
\hline MSHQ-EJD, mean \pm SD & $0.90 \pm 2.56$ & $0.25 \pm 2.31$ \\
\hline SQoL-M, mean \pm SD & $2.43 \pm 2.89$ & $1.21 \pm 3.44$ \\
\hline
\end{tabular}

${ }^{\mathrm{a}} P<0.05$ versus baseline; ${ }^{\mathrm{b}} P<0.05$ versus Group B.

function, and overall satisfaction. In fact, it should be noted that the severity of penile curvature or deformity may significantly contribute to man's inability to have intercourse.

Furthermore, patients referred the improvement of ejaculation and quality of life, as assessed by the MSHQ-EjD and the SQoL-M), although there was a short follow-up.

This new natural compound is thought to play an important double role (therapeutic and antiaging), on cavernous tissue, by acting on the etiopathogenetic aspects of ED, mainly the microstructural alteration of the corpus cavernosum tissues, following inflammation and/or oxidative damage [16].

We suppose that this combination of natural compounds may strength the efficacy of the single component, the Ecklonia bicyclis by a radical scavenger activity, the protodioscin by binding and activating the receptor of testosterone, and the glucosamine oligosaccharide, by acting on the nonadrenergic and noncholinergic system (NANC) and on the endothelial

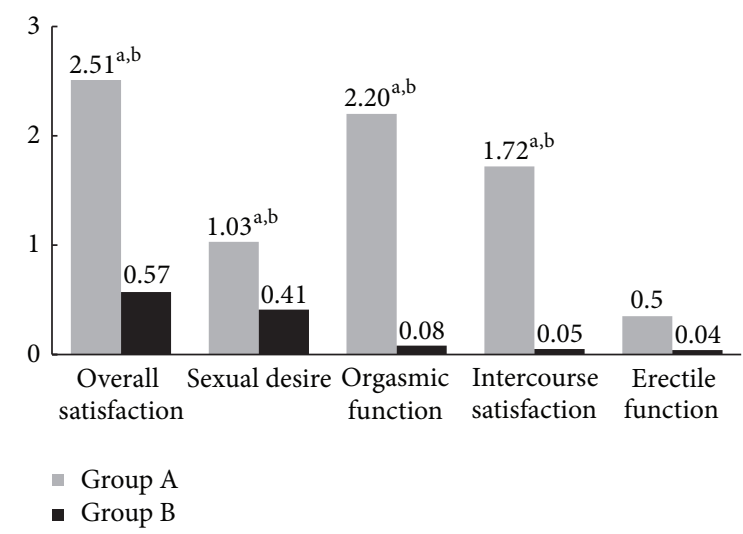

FIgURE 2: Mean changes from baseline to 3 months for International Index of Erectile Function domain $\left({ }^{\mathrm{a}} \mathrm{P}<0.05\right.$, versus baseline; ${ }^{\mathrm{b}} \mathrm{P}<$ 0.05, versus Group B).

cell system as a strong nitric oxide synthetase (NOS) stimulator, thus improving the concentration of nitric oxide (NO) in the smooth cells inside the corpus cavernosum.

These considerations may explain the significant changes of IIEF-EF, MSHQ-EjD, PSV, and SQoL-M in Group A for men with moderate arterial penile dysfunction. We can affirm in fact that those with severe arterial dysfunction may not have benefits from therapy with natural compounds, since their ED was worse.

Penile CDU evaluation in ED has a significant role in determining the cause of ED. Arteriogenic ED or arterial insufficiency is diagnosed when PSV is $<25 \mathrm{~cm} / \mathrm{s}$, with angiographic correlation showing that a PSV threshold of $25 \mathrm{~cm} / \mathrm{s}$ has $92 \%$ accuracy in diagnosis of arterial integrity. Penile CDU represents an accurate tool to investigate cavernous artery inflow and venous leakage frequently used for assessing the efficacy of several genitourethral reconstruction surgical techniques, in patients who underwent urethroplasty, peyronie's disease related surgery, or penile revascularization $[27,28]$.

In this context, although the prevalence of ED before and after genitourethral reconstruction surgeries has not been correctly investigated, it may affect the expectancy of these techniques with failed results.

Although our population study was represented by subjects who did not underwent previous genitourethral reconstruction surgeries, we may suggest with caution to use oral therapy with alga Ecklonia bicyclis, Tribulus terrestris, and glucosamine oligosaccharide with the intention to ameliorate penile CDU in patients eligible for penile surgery.

However, this study is not depicted from limitations. First of all a longer follow-up would have added more information about the efficacy and its maintenance over the time. Second, ED was assessed by questionnaire and penile Doppler ultrasound and ejaculation function by the MSHQED. Certainly, some more diagnostic procedures would have been beneficial. In conclusion, oral therapy with alga Ecklonia bicyclis, Tribulus terrestris, and glucosamine oligosaccharide has significant advantages in patients with mild-moderate 
ED, by improving intercourse satisfaction, sexual desire, orgasmic function, overall satisfaction, ejaculation function, and quality of life. Further clinical study, involving a general population eligible for genitourethral reconstruction surgery may offer new insight about the efficacy of combination with alga Ecklonia bicyclis, Tribulus terrestris, and glucosamine oligosaccharide.

\section{Conclusion}

Patients affected by mild-moderate ED may significantly benefit from oral therapy with alga Ecklonia bicyclis, Tribulus terrestris, and glucosamine oligosaccharide by improving sexual and ejaculation function and sexual quality of life. In particular, those with moderate arterial dysfunction, considered as a peak systolic velocity (PSV) $\geq 25$ and $<35 \mathrm{~cm} / \mathrm{s}$, may significantly benefit from this therapy thanks to the improvement of IIEF-EF, MSHQ, SQoL-M, and PSV.

\section{Conflict of Interests}

The authors declare that there is no conflict of interests regarding the publication of this paper.

\section{References}

[1] P. Montorsi, P. M. Ravagnani, S. Galli et al., "Association between Erectile Dysfunction and Coronary Artery Disease: matching the Right Target with the right test in the right patient," European Urology, vol. 50, no. 4, pp. 721-731, 2006.

[2] J. I. Mäkinen, A. Perheentupa, O. T. Raitakari, M. Koskenvuo, P. Pöllänen, and I. Huhtaniemi, "Sexual symptoms in aging men indicate poor life satisfaction and increased health service consumption," Urology, vol. 70, no. 6, pp. 1194-1199, 2007.

[3] G. Jackson, R. C. Rosen, R. A. Kloner, and J. B. Kostis, "The second Princeton consensus on sexual dysfunction and cardiac risk: new guidelines for sexual medicine," The Journal of Sexual Medicine, vol. 3, no. 1, pp. 28-36, 2006.

[4] V. Favilla, S. Cimino, C. Salamone et al., "Risk factors of sexual dysfunction after transurethral resection of the prostate (TURP): a 12 months follow-up," Journal of Endocrinological Investigation, vol. 36, pp. 1094-1098, 2013.

[5] A. Salonia, G. Castagna, A. Saccà et al., "Is erectile dysfunction a reliable proxy of general male health status? The case for the international index of erectile function-erectile function domain," The Journal of Sexual Medicine, vol. 9, no. 10, pp. 27082715, 2012.

[6] R. O. Rosen, W. A. Fisher, I. Eardley, C. Niederberger, A. Nadel, and M. Sand, “The multinational Men's Attitudes to Life Events and Sexuality (MALES) study: I. Prevalence of erectile dysfunction and related health concerns in the general population," Current Medical Research and Opinion, vol. 20, no. 5, pp. 607-617, 2004.

[7] K.-K. Chew, J. Finn, B. Stuckey et al., "Erectile dysfunction as a predictor for subsequent atherosclerotic cardiovascular events: findings from a linked-data study," The Journal of Sexual Medicine, vol. 7, no. 1, pp. 192-202, 2010.

[8] C. Vlachopoulos, K. Rokkas, N. Ioakeimidis, and C. Stefanadis, "Inflammation, metabolic syndrome, erectile dysfunction, and coronary artery disease: common links," European Urology, vol. 52, no. 6, pp. 1590-1600, 2007.

[9] J.-Y. Dong, Y.-H. Zhang, and L.-Q. Qin, "Erectile dysfunction and risk of cardiovascular disease: meta-analysis of prospective cohort studies," Journal of the American College of Cardiology, vol. 58, no. 13, pp. 1378-1385, 2011.

[10] B. P. Gupta, M. H. Murad, M. M. Clifton, L. Prokop, A. Nehra, and S. L. Kopecky, "The effect of lifestyle modification and cardiovascular risk factor reduction on erectile dysfunction: a systematic review and meta-analysis," Archives of Internal Medicine, vol. 171, no. 20, pp. 1797-1803, 2011.

[11] G. I. Russo, S. Cimino, E. Fragala et al., "Insulin resistance is an independent predictor of severe lower urinary tract symptoms and of erectile dysfunction: results from a cross-sectional study," The Journal of Sexual Medicine, 2014.

[12] R. C. Ma, W. So, X. Yang et al., "Erectile dysfunction predicts coronary heart disease in type 2 diabetes," Journal of the American College of Cardiology, vol. 51, no. 21, pp. 2045-2050, 2008.

[13] K. Hatzimouratidis, E. Amar, I. Eardley et al., "Guidelines on male sexual dysfunction: erectile dysfunction and premature ejaculation,” European Urology, vol. 57, no. 5, pp. 804-814, 2010.

[14] A. Tsertsvadze, F. Yazdi, H. A. Fink et al., "Oral sildenafil citrate (viagra) for erectile dysfunction: a systematic review and metaanalysis of harms," Urology, vol. 74, no. 4, pp. 831.e8-836.e8, 2009.

[15] P. Dorsey, C. Keel, M. Klavens, and W. J. G. Hellstrom, "Phosphodiesterase type 5 (PDE5) inhibitors for the treatment of erectile dysfunction," Expert Opinion on Pharmacotherapy, vol. 11, no. 7, pp. 1109-1122, 2010.

[16] F. Iacono, D. Prezioso, E. Illiano, G. Romeo, A. Ruffo, and B. Amato, "Sexual asthenia: Tradamixina versus Tadalafil $5 \mathrm{mg}$ daily," BMC Surgery, vol. 12, supplement 1, article S23, 2012.

[17] V. Favilla, G. I. Russo, S. Privitera et al., "Combination of intralesional verapamil and oral antioxidants for Peyronie's disease: a prospective, randomised controlled study," Andrologia, 2013.

[18] G. Morgia, S. Cimino, V. Favilla et al., "Effects of Serenoa repens, selenium and lycopene (Profluss) on chronic inflammation associated with benign prostatic hyperplasia: results of "FLOG" (Flogosis and Profluss in Prostatic and Genital Disease), a multicentre Italian study," International Brazilian Journal of Urology, vol. 39, no. 2, pp. 214-221, 2013.

[19] M. K. Cathcart, "Regulation of superoxide anion production by NADPH oxidase in monocytes/macrophages: contributions to atherosclerosis," Arteriosclerosis, Thrombosis, and Vascular Biology, vol. 24, no. 1, pp. 23-28, 2004.

[20] K. K. Griendling, D. Sorescu, and M. Ushio-Fukai, "NAD(P)H oxidase: role in cardiovascular biology and disease," Circulation Research, vol. 86, no. 5, pp. 494-501, 2000.

[21] E. Vicari, S. la Vignera, R. Condorelli, and A. E. Calogero, "Endothelial antioxidant administration ameliorates the erectile response to PDE5 regardless of the extension of the atherosclerotic process," Journal of Sexual Medicine, vol. 7, no. 3, pp. 1247-1253, 2010.

[22] P. Li, R. Dietz, and R. Von Harsdorf, "Differential effect of hydrogen peroxide and superoxide anion on apoptosis and proliferation of vascular smooth muscle cells," Circulation, vol. 96, no. 10, pp. 3602-3609, 1997.

[23] L. Minutoli, A. Bitto, F. Squadrito et al., "Serenoa repens, lycopene and selenium: a triple therapeutic approach to manage benign prostatic hyperplasia," Current Medicinal Chemistry, vol. 20, no. 10, pp. 1306-1312, 2013. 
[24] L. Vanella, G. I. Russo, S. Cimino, E. Fragala, V. Favilla, and G. li Volti, "Correlation between lipid profile and heme oxygenase system in patients with benign prostatic hyperplasia," Urology, vol. 83, no. 6, pp. 1444.e7-1444.e13, 2014.

[25] S. la Vignera, R. Condorelli, E. Vicari, R. D’agata, and A. E. Calogero, "Endothelial antioxidant compound prolonged the endothelial antiapoptotic effects registered after tadalafil treatment in patients with arterial erectile dysfunction," Journal of Andrology, vol. 33, no. 2, pp. 170-175, 2012.

[26] S. C. Kam, J. M. Do, J. H. Choi, B. T. Jeon, G. S. Roh, and J. S. Hyun, "In vivo and in vitro animal investigation of the effect of a mixture of herbal extracts from Tribulus terrestris and Cornus officinalis on penile erection," Journal of Sexual Medicine, vol. 9, no. 10, pp. 2544-2551, 2012.

[27] E. Chung, H. Yan, L. de Young, and G. B. Brock, "Penile Doppler sonographic and clinical characteristics in Peyronie's disease and/or erectile dysfunction: an analysis of 1500 men with male sexual dysfunction," BJU International, vol. 110, no. 8, pp. 12011205, 2012.

[28] O. Kayigil, E. Okulu, M. Aldemir, and E. Onen, "Penile revascularization in vasculogenic erectile dysfunction (ED): long-term follow-up," BJU International, vol. 109, no. 1, pp. 109-115, 2012. 


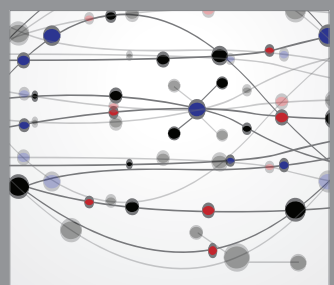

The Scientific World Journal
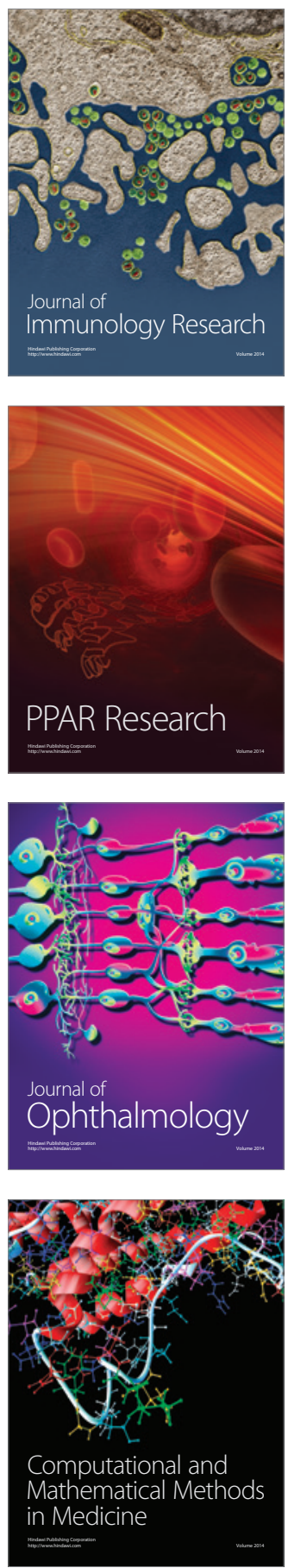

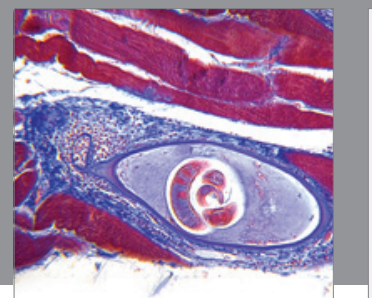

Gastroenterology

Research and Practice
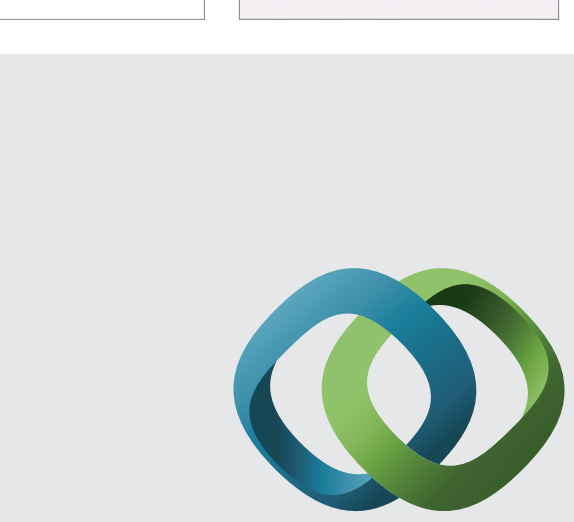

\section{Hindawi}

Submit your manuscripts at

http://www.hindawi.com
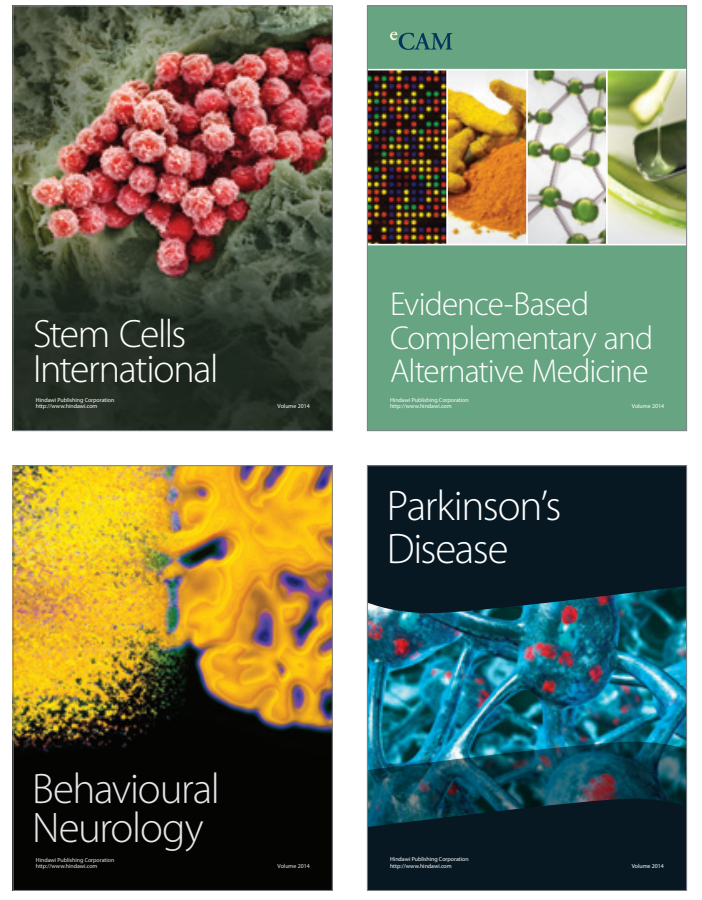
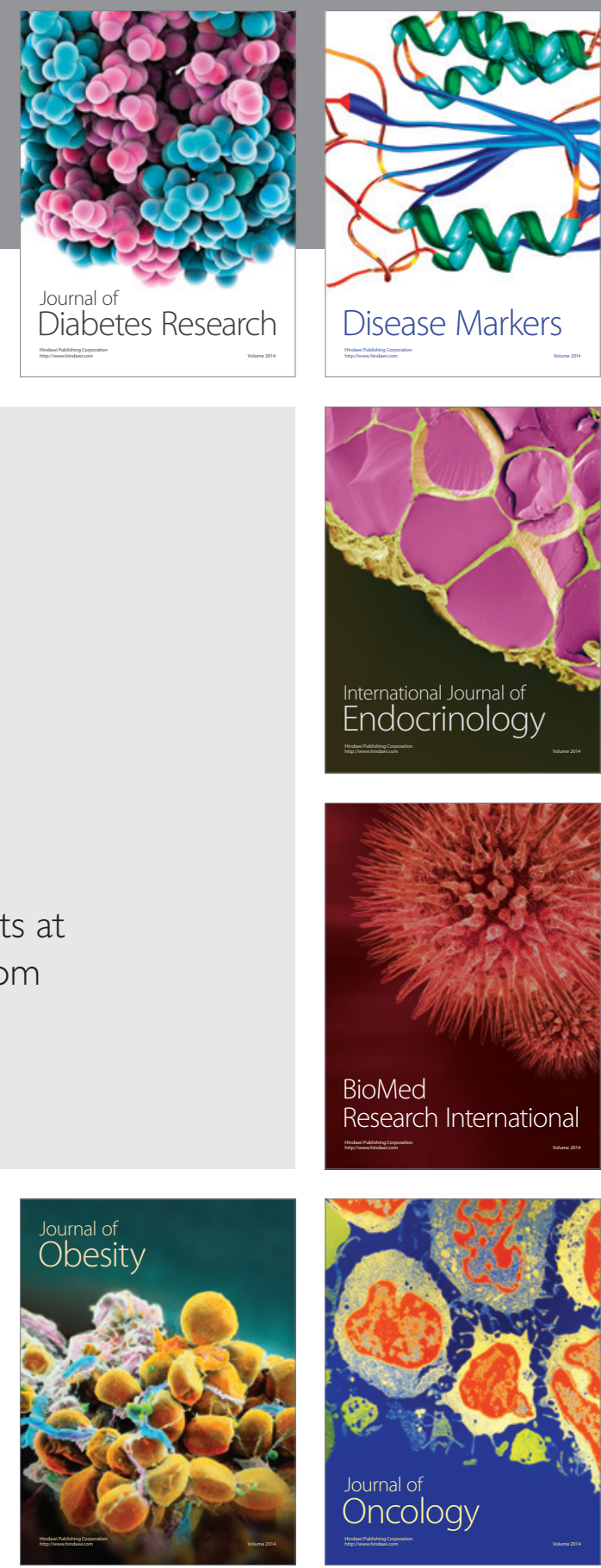

Disease Markers
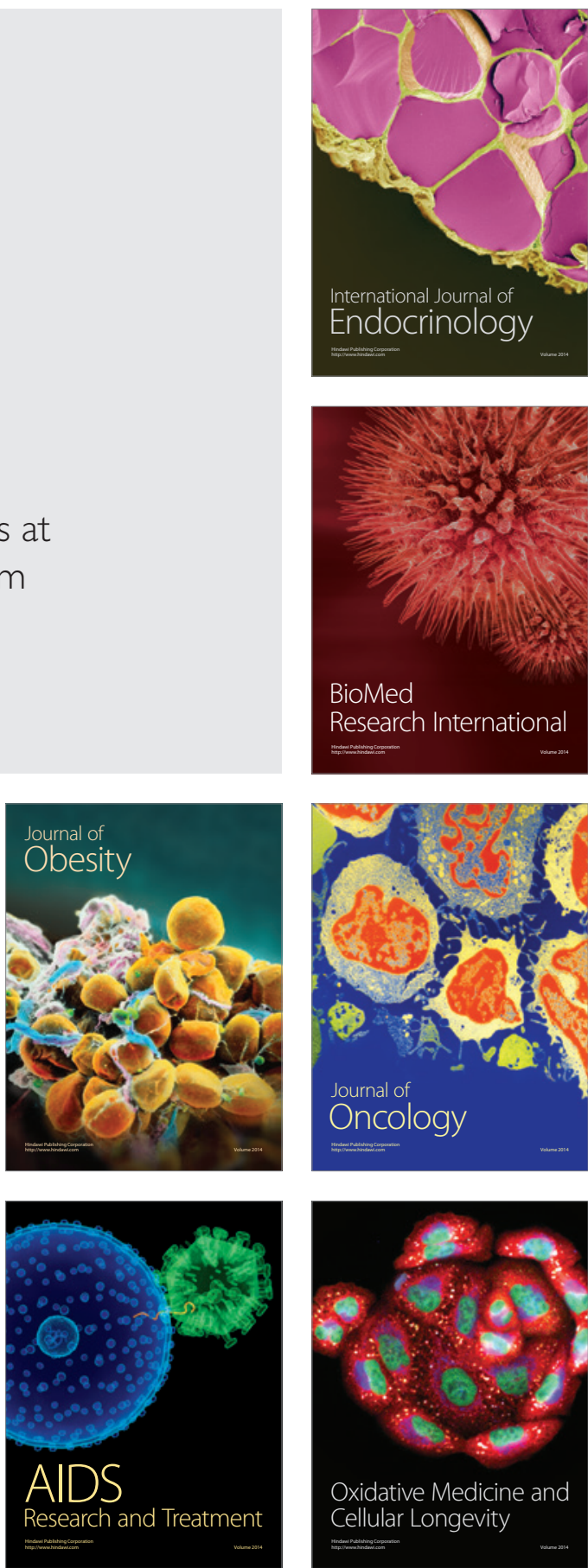